\title{
O CONTROLE DE CONSTITUCIONALIDADE NO BRASIL: DILEMAS HISTÓRICOS DO SUPREMO TRIBUNAL FEDERAL E AS REFORMAS DO SÉCULO XXI
}

\author{
${ }^{1}$ Carlos Victor Muzzi Filho \\ ${ }^{2}$ Antônio Carlos Diniz Murta
}

\section{RESUMO}

Neste artigo é examinada a crise do Supremo Tribunal Federal (STF), a incapacidade de o STF julgar todos os processos que lhe são submetidos. São examinadas as mudanças que ocorreram ao longo da história, especialemente as reformas realizadas no século XXI. Afirma-se que, em razão dessas, há um novo modelo de controle de constitucionalidade brasileiro, e não mais a convivência dos tradicionais modelos concentrado e difuso. Afirmase, ainda, que as reformas implementadas desde os anos 2000 não serão suficientes para resolver a crise do STF, sendo necessário reduzir as competências jurisdicionais do STF.

Palavras-chave: Constitucionalismo, Controle de constitucionalidade, Crise do supremo tribunal federal, Novo modelo de controle de constitucionalidade brasileiro

\section{EL CONTROL DE LA CONSTITUCIONALIDAD EN BRASIL: DILEMAS HISTÓRICOS DE LA CORTE SUPREMA DE JUSTICIA Y LAS REFORMAS DEL SIGLO XXI}

\section{RESUMEN}

En este trabajo se examina la crisis de la Corte Suprema (STF), la incapacidad de la Corte Suprema de juzgar todos los casos sometidos a su conocimiento. Se examinan los cambios que se han producido en la historia, especialemente reformas llevadas a cabo en el siglo XXI. Se dice que a causa de esto, hay un nuevo modelo brasileño de control del constitucionalidad, e no más la coexistencia de los modelos concentrados y difusos. Se afirma además que las reformas implementadas desde la década de 2000 no serán suficientes para resolver la crisis de la Corte Suprema.

Palabras-claves: Constitucionalismo, El control judicial de la constitucionalidad, Crisis de la corte suprema, Nuevo modelo de revisión judicial brasileño

\footnotetext{
${ }^{1}$ Doutor em Direito pela Universidade Federal de Minas Gerais - UFMG, Belo Horizonte, Brasil. Professor Assistente II da Universidade FUMEC, Belo Horizonte, nos Cursos de Graduação e Mestrado. E-mail: muzzi@fumec.br

2 Doutor em Direito Comercial pela Universidade Federal de Minas Gerais - UFMG, Brasil. Professor Assistente II da Universidade FUMEC/MG nos Cursos de Graduação e Mestrado. E-mail: acmurta@ fumec.br
} 


\section{INTRODUÇÃO}

Destina-se o presente artigo ao grupo de estudo "Estado, Constitucionalismo e Sociedade”, porque o objetivo do artigo é apreciar alguns aspectos do percurso histórico cumprido pelo Supremo Tribunal Federal (STF), tribunal máximo do sistema jurídico brasileiro, que também exerce as funções de corte constitucional. Buscam os autores, a partir dessa perspectiva histórica, identificar as principais dificuldades estruturais do STF, que o impedem de cumprir, com eficiência e de modo pleno, as relevantes funções de corte constitucional. Examinam, ainda, as reformas constitucionais e legais, efetivadas já no século XXI, no sistema brasileiro de controle de constitucionalidade.

Inicialmente, cabe ressaltar que, sob o ângulo jurídico, o constitucionalismo pode ser compreendido, na lição de José Joaquim Gomes Canotilho, como "uma técnica específica de limitação do poder com fins garantísticos”, razão pela qual o constitucionalismo ergue o "princípio do governo limitado indispensável à garantia dos direitos em dimensão estruturante da organização político-social de uma comunidade" (CANOTILHO, 2003, p. 51, “passim”). Nesse mesma linha, Maurizio Fioravanti também registra que "el constitucionalismo es concebido como el conjunto de doctrinas que aproximadamente a partir de la mitad del siglo XVII se han dedicado a recuperar en el horizonte de la constitución de los modernos el aspecto del limite y de la garantia" (FIORAVANTI, 2007, p. 85).

Nesse contexto, assume especial relevância, no constitucionalismo, o controle de constitucionalidade das leis, notadamente o controle jurisdicional de constitucionalidade das leis. Esse controle é, novamente com Canotilho, "um dos mais relevantes instrumentos do controlo do cumprimento e observância das normas constitucionais", sendo inequívoco o seu papel de "garantia de observância da Constituição" (CANOTILHO, 2003, p. 889, “passim”). Pertinente, pois, a discussão proposta com os objetivos do grupo de trabalho.

Assim, em uma primeira etapa, será feito breve exame da história do controle de constitucionalidade no sistema brasileiro, apontando-se as dificuldades estruturais do STF para realizar, ao longo do tempo, esse controle. Em seguida, serão examinados os mecanismos propostos pelo legislador brasileiro, já no século XXI, veiculados pela Emenda Constitucional $\mathrm{n}^{\circ}$ 45, de 8 de dezembro de 2004 (apelidada de Emenda da Reforma do Judiciário) e por várias alterações no Código de Processo Civil ainda em vigor (Lei no 5.869, de 11 de janeiro de 1973, CPC/1973), culminando com a aprovação 
do novo Código de Processo Civil (CPC/2015), aprovado pela Lei n ${ }^{\circ} 13.105$, de 16 de março de 2015, que entrará em vigor em 18 de março de 2016.

O objetivo desse confronto é questionar a eficácia das alterações legislativa, mas, desde já, se anuncia a hipótese do presente artigo, qual seja, a de que as mudanças havidas na Constituição Federal e na legislação processual, conquanto apresentem alguns efeitos positivos, se mostram insuficientes para resolver os graves problemas estruturais do STF. É muito provável, considerando a experiência já vivida, que o CPC/2015 não resulte em grandes alterações na prática forense do controle de constitucionalidade das leis brasileiras, assim como já ocorreu em relação a outras alterações legislativas que se fizeram no sistema brasileiro.

Mais do que apreciar questões teóricas (que também existem), o objetivo é examinar a realidade forense, isto é, as dificuldades estruturais com que o STF convive, há muitos anos, e, efetivamente, comprometem a eficiência e a qualidade do controle de constitucionalidade exercido pelo tribunal. O exame dessa realidade será feito a partir de dados estatísticos, sejam aqueles disponíveis no "site” do próprio STF, sejam ainda dados coletados em outros trabalhos de pesquisa. A propósito, a proliferação, nos últimos anos, de trabalhos jurídicos que envolvem pesquisas empíricas (com coleta de dados estatísticos dos diversos tribunais brasileiros) ${ }^{1}$, além de ser altamente louvável do ponto de vista da pesquisa acadêmica, é inequívoco sinal de que essa realidade forense já não é ignorada pela academia.

Teorias jurídicas sobre o controle de constitucionalidade da lei (sua legitimidade, seus instrumentos, sua extensão) tornar-se-ão irrelevantes para a sociedade brasileira, se forem desconsideradas as dificuldades materiais que turbam o exercício desse controle pelo STF (e pelo Poder Judiciário, de modo mais amplo). Obviamente, não se propõe rechaçar o estudo dessas teorias jurídicas, mas considerar, na compreensão dessas teorias, o terreno brasileiro em que elas serão lançadas, mesmo porque, inegavelmente, tais teorias foram forjadas em países e realidades diferentes, a partir das dificuldades e peculiaridades lá existentes em determinada época.

Ademais, propõe-se, neste trabalho, a tese de que o sistema brasileiro de controle jurisdicional de constitucionalidade, que durante vários anos conviveu com a aplicação simultânea dos modelos difuso e concentrado de controle de constitucionalidade, ganhou, a partir das reformas implementadas já neste século XXI, nova configuração,

\footnotetext{
${ }^{1}$ Apenas a título ilustrativo, podem ser mencionados trabalhos de Joaquim Falcão, Pablo Cerdeira e Diego Werneck Arguelhes (FALCÃO, CERDEIRA; e ARGUELHES, 2011); e Carlos Ari Sundfeld e outros (SUNDFELD; RIZZI; CARDOSO “et alii”, 2010); além dos trabalhos organizados por Daniela Monteiro Gabbay e Luciana Gross Cunha (GABBAY; e CUNHA, 2012).
} 
que não mais pode ser entendida como a da convivência daqueles dois modelos. Há, efetivamente, um novo modelo de controle de constitucionalidade híbrido, resultante da simbiose entre os clássicos modelos difuso e concentrado de controle de constitucionalidade, que resultaram no peculiar modelo brasileiro de controle de constitucionalidade.

Encerrando essa apresentação, os autores pontuam que, obviamente, não têm soluções (ou $a$ solução) para as dificuldades estruturais do STF. O controle de constitucionalidade, assim como o constitucionalismo, não é fruto de propostas teóricas, mas, ao invés, resultado de longos e tortuosos processos históricos, que se estendem, interminavelmente, pelo percurso traçado pela própria humanidade. Há, portanto, neste trabalho, algumas constatações que permitem aos autores apontar perspectivas que se desenham para o sistema brasileiro de controle de constitucionalidade, tendo em vista a realidade existente e as mudanças que ele vêm sofrendo ao longo dos últimos quinze anos. Portanto, os autores compartilham dúvidas, muito antes de apresentarem certezas sobre o tema em discussão.

\section{A “CRISE DO STF” E AS TENTATIVAS DE SOLUÇÃO NO SÉCULO XX: “CRISE” PERMANENTE}

No Brasil, após a instauração da República, em 1889, adotou-se, na Constituição Federal promulgada em 1891, o chamado modelo difuso de controle jurisdicional de constitucionalidade das leis e atos normativos, por influência direta dos Estados Unidos da América (EUA) $)^{2}$. Ao STF atribuiu-se, em última instância processual, a decisão final sobre a constitucionalidade, ou não, de leis ou atos normativos, o que era feito por intermédio, principalmente, do recurso extraordinário.

Não existia, propriamente, uma corte constitucional, até porque esse modelo somente veio a ser efetivamente implementado, na Europa, no início do século XX, visto que o STF possuía - como ainda possui - outras atribuições jurisdicionais que nada têm a ver com o controle de constitucionalidade de leis e atos normativos. Aliás, como adiante anotado, até a promulgação da atual Constituição Federal, em 5 de outubro de 1988, o recurso extraordinário poderia ter objeto, além de questões

\footnotetext{
${ }^{2}$ Nesse sentido, por todos, Gilmar Mendes, Inocêncio Mártires Coelho e Paulo Gustavo Gonet Branco, que invocam as lições de Celso Agrícola Barbi e Oswaldo Aranha Bandeira de Mello (MENDES; COELHO; e BRANCO, 2008, p. 1.034). Em sentido oposto, contudo, veja-se a tese sustentada por Marcelo Casseb Continentino, que identifica, no período imperial brasileiro, a existência do controle de constitucionalidade de leis (CONTINENTINO, 2015).
} 
constitucionais, também questões de direito federal.

Recorde-se que o modelo difuso sempre sofreu críticas, que levaram à proposição teórica do chamado modelo concentrado de controle de constitucionalidade, que somente foi implementado no século XX, especialmente na Europa continental. Dentre as críticas feitas ao modelo difuso, destaca-se aquela atinente à insegurança jurídica decorrente da possibilidade de haver decisões contraditórias sobre a constitucionalidade, ou não, de determinada lei. Isso porque, sendo exercido por qualquer juiz, o controle de constitucionalidade pelo modelo difuso resultava, não raras vezes, em decisões contraditórias, emanadas de órgãos judiciais diversos.

Nos países do "Common Law”, notadamente nos EUA, essa insegurança era reduzida pela força vinculante do precedente judicial, uma vez que os juízes estavam obrigados, pela tradição, a respeitar as decisões dos tribunais superiores ("stare decisis"). Nos países do "Civil Law", contudo, não havendo essa força vinculante dos precedentes, aumentava "aquele perigo de conflitos e de caótica incerteza do direito, de que se falou antes" (CAPPELLETTI, 1984, p. 83).

Com o objetivo, então, de atenuar a insegurança decorrente do modelo difuso de controle de constitucionalidade, o Brasil adotou, a partir da Constituição de 1934 (artigo 179), a chamada cláusula de reserva de plenário. Essa regra tornou-se tradicional no sistema jurídico brasileiro, estando assim expressa no artigo 97 da atual Constituição Federal de 1988: "Somente pelo voto da maioria absoluta de seus membros ou dos membros do respectivo órgão especial poderão os tribunais declarar a inconstitucionalidade de lei ou ato normativo do Poder Público”.

A cláusula de reserva de plenário foi, ainda, objeto da Súmula Vinculante $n^{\circ} 10$, do Supremo Tribunal Federal, que lhe precisou o significado: "Viola a cláusula de reserva de plenário (CF, artigo 97) a decisão do órgão fracionário de Tribunal que, embora não declare expressamente a inconstitucionalidade de lei ou ato normativo do poder público, afasta sua incidência, no todo ou em parte”. Editou-se essa súmula porque eram comuns as decisões dos tribunais que recusavam aplicação ao artigo 97 da Constituição Federal de 1988, ao argumento de que a decisão do tribunal não estaria declarando a inconstitucionalidade da lei em discussão, mas apenas afastando sua aplicação no caso concreto. O STF reafirmou, então, a tese de que o reconhecimento, ainda que incidental, da inconstitucionalidade de lei ou ato normativo deve ser feito, nos tribunais, pelo plenário ou pelo órgão especial da corte.

Entretanto, para além da insegurança jurídica peculiar ao modelo difuso (quando adotado em países vinculados ao "Civil Law", sem a cultura do precedente judicial), no 
Brasil, mais grave se revelou a incapacidade do STF em julgar, com a necessária celeridade processual, todos os recursos extraordinários que lhe eram dirigidos pelas instâncias inferiores.

Desde os anos 1940, no Brasil, se discute a chamada "crise do Supremo", que foi também denominada “crise do recurso extraordinário” (MANCUSO, 2013, p. 71, citando entendimento manifestado pelo Ministro Moreira Alves, do STF). No início dos anos 1940, em artigo doutrinário, Philadelpho Azevedo, então Ministro do STF, se impressionava com o aumento do número de recursos extraordinários anualmente interpostos perante o STF, que haviam passado de 150 (cento e cinquenta) recursos, em 1935, para 1.133 (mil, cento e trinta e três) recursos, em 1942, razão pela qual apontava a necessidade de criação de mecanismos que tornassem possível ao STF julgar todas as causas que lhe eram submetidas (AZEVEDO, 1942, p. 8/9).

Alfredo Buzaid, que também foi Ministro do STF, referiu-se igualmente à "crise do Supremo Tribunal Federal”, definindo-a como o "desequilíbrio entre o número de feitos protocolados e o de julgamento por ele proferidos; sendo a entrada daqueles consideravelmente superior à capacidade de sua decisão, vão se acumulando os processos não julgados, resultando daí o congestionamento” (BUZAID, 1960, p. 346, “passim”).

Desde meados do século XX, então, foram sendo criados os mais variados mecanismos (estruturais e processuais) que possibilitassem ao STF superar a crise. No plano estrutural, já em 1937, fez-se a divisão do STF em duas turmas, com o objetivo de se agilizar o julgamento dos recursos extraordinários (BUZAID, 1960, p. 347), medida que não impediu o progressivo aumento do congestionamento do STF. Já no plano processual, várias medidas foram sendo adotadas, como registra Ilmar Galvão (GALVÃO, 1991, p. 85), que também foi Ministro do STF, como a adoção, em 1958, do duplo juízo de admissibilidade do recurso extraordinário, exercido pelos presidentes dos Tribunais recorridos e, depois, pelo próprio STF; a adoção das súmulas de jurisprudência predominante, a partir de $1963^{3}$; e as exigências formalistas previstas no Regimento Interno do STF, “que, na verdade, configuravam causas de exclusão de admissibilidade do recurso extraordinário, como o que se constituiu, no dizer de José

\footnotetext{
${ }^{3}$ Dentre essas súmulas, devem ser mencionadas, dentre outras, a Súmula $\mathrm{n}^{\circ} 282$, do STF, que definiu a exigência do prequestionamento da questão constitucional como requisito para admissão do recurso extraordinário, e a Súmula $n^{\circ} 279$, do STF, que vetou a rediscussão de questões fáticas em sede de recurso extraordinário.
} 
Guilherme Villela, um verdadeiro campo minado entre a Nação e o Supremo" (GALVÃO, 1991, p. 85) ${ }^{4}$.

A crise, contudo, ainda assim não foi resolvida, motivo pelo qual, ao longo de todo o século passado, várias reformas de natureza processual foram efetivadas e, conquanto pudessem obter algum benefício inicial, eram meros paliativos, incapazes de resolver, definitivamente, o congestionamento de processos no STF.

A Constituição Federal de 1988, promulgada após o fim da ditadura militar (1964-1985), fez modificação estrutural bem mais radical, com o objetivo de, novamente, tentar resolver a crise do STF. Alterou-se, então, e de modo substancial, o antigo modelo de recurso extraordinário, que foi, a partir de 1988, separado em dois recursos distintos.

Nas Constituições anteriores a 1988, tanto questões constitucionais, quanto questões de direito federal, poderiam ser objeto do recurso extraordinário, cabível, assim, nos casos em que houvesse violação à Constituição ou à lei federal. A Constituição Federal de 1988, criando o Superior Tribunal de Justiça (STJ), separou o antigo recurso extraordinário em dois outros recursos: a) o recurso extraordinário para o STF, envolvendo apenas questões constitucionais; e b) o recurso especial (REsp) para o STJ, envolvendo apenas questões de direito federal ${ }^{5}$.

O objetivo principal dessa alteração foi transformar o STF em verdadeira corte constitucional, atribuindo-se a outros tribunais superiores a função de tribunal de última instância em relação à legislação trabalhista (Tribunal Superior do Trabalho, TST), à legislação eleitoral (Tribunal Superior Eleitoral, TSE), à legislação militar (Superior Tribunal Militar, STM), e ao direito federal em geral (Superior Tribunal de Justiça, STJ $)^{6}$.

Teoricamente, a alteração estrutural feita pela Constituição Federal de 1988 contribuiria para reduzir o número de recursos extraordinários dirigidos ao STF, por ser inegável a redução substancial de matérias que poderiam ser discutida no recurso

\footnotetext{
${ }^{4}$ No mesmo tom, também Rodolfo de Camargo Mancuso relaciona várias "tentativas já implementadas para, de algum modo equacionar o volume excessivo de recursos aos STF", como a arguição de relevância, de 1975, e os vários "óbices regimentais" (MANCUSO, 2013, p. 76/99, "passim”).

${ }^{5}$ José Afonso da Silva, na década de 1960, também preconizava a redução das matérias passiveis de serem discutidas na via do recurso extraordinário, entendendo que esse acúmulo seria uma das principais causa da crise do $S T F$, juntamente com o reduzido número de Ministros, preconizando, por isso, a criação de um outro tribunal, o "Tribunal Superior de Justiça", que, juntamente com o TSE e o TST, que já existiam naquela época. Essa criação, pontuava José Afonso da Silva, "solucionará, indubitavelmente, a crise do Supremo, porque, no mínimo, sessenta ou setenta por cento dos feitos, em Recurso Extraordinários, são-lhe tirados da competência e distribuídos" (SILVA, 1963, p. 456, "passim”).

${ }^{6}$ Frise-se que apenas a competência do STJ é definida pela própria Constituição. Quanto aos demais tribunais superiores, compete à lei complementar definir suas competências, o que é feito nos termos indicados no texto acima.
} 
extraordinário, considerando-se, em termos comparativos, as disposições das Constituições anteriores e a Constituição Federal de 1988. Na prática, contudo, a alteração feita pela Constituição Federal de 1988 não provocou a redução do número de recursos extraordinários, não se resolvendo, então, a crise do STF .

Veja-se, a título de exemplo, que, em 1990 e em 1991, foram distribuídos pouco mais de 10.000 (dez mil) recursos extraordinários em cada ano. Já em 1997, o número de recursos extraordinários chegou a quase 15.000 (quinze mil), ultrapassando a casa dos 44.000 (quarenta e quatro mil) recursos extraordinários em 2003 e alcançando a inacreditável marca de 54.575 (cinquenta e quatro mil, quinhentos e setenta e cinco) recursos extraordinários em $2006^{7}$.

Não é objetivo deste trabalho discutir as causas desse aumento expressivo no número de recurso extraordinários, mas se pode apontar como causa evidente o “compromisso maximizador” da Constituição Federal de 1988, expressão adotada por Oscar Vilhena Vieira para explicar porque "a Constituição transcendeu os temas propriamente constitucionais e regulamentou pormenorizada e obsessivamente um amplo campo das relações sociais, econômicas e públicas, numa espécie de compromisso maximizador” (VIEIRA, 2009, p. 489). Dessa ampla regulamentação constitucional surgiu, ainda com Oscar Vilhena Vieira, "uma enorme esfera de tensão constitucional e consequentemente gerou uma explosão da litigiosidade constitucional" (VIEIRA, 2009, loc. cit.).

Além da alteração na sistemática do recurso extraordinário, cabe acrescentar que a Constituição Federal de 1988 também produziu outra importante mudança estrutural no sistema de controle de constitucionalidade, qual seja, a sensível ampliação do modelo concentrado de constitucionalidade das leis e atos normativos.

Antes da Constituição Federal de 1988, o controle de constitucionalidade, pelo modelo concentrado, foi implementado, de forma efetiva, a partir da Emenda Constitucional $n^{\circ} 16$, de 26 de novembro de 1965, que instituiu a competência originária do STF para apreciar e julgar a representação de inconstitucionalidade (MENDES, 2005, p. 68) ${ }^{8}$. Todavia, apenas o Procurador-Geral da República (Ministério Público

\footnotetext{
${ }^{7}$ Informações estatísticas sobre o número e o tipo de processos e recursos distribuídos no Supremo Tribunal Federal estão disponíveis no "site" do próprio tribunal, no endereço eletrônico http://www.stf.jus.br/portal/cms/verTexto.asp?servico=estatistica\&pagina=REAIProcessoDistribuido. As informações aqui utilizadas foram retiradas dos quadros disponíveis para consulta pública. Confira-se, ainda, referências feitas por Rodolfo de Camargo Mancuso (MANCUSO, 2013, p. 70/71) e por Alfredo Buzaid (BUZAID, 1960, p. 346/347).

${ }^{8}$ Predomina, no Brasil, a tese de que o modelo concentrado foi implantado já na Constituição Federal de 1934, com a criação da chamada ação direta interventiva. A Constituição de 1934, porém, teve curta existência, sendo substituída pela Constituição Federal de 1937, promulgada durante a ditadura de Getúlio
} 
Federal) detinha legitimidade para o ajuizamento da representação de inconstitucionalidade, o que tornava restrita a utilização do modelo concentrado. Essa sistemática foi mantida pela Constituição Federal de 1967 (outorgada pela ditadura militar) e pela Emenda Constitucional n 1, de 1969 (que correspondeu, na verdade, a um novo texto constitucional, também outorgado pela ditadura militar).

A Constituição Federal de 1988, como anotado, inegavelmente ampliou o modelo concentrado, notadamente porque ampliou a legitimidade para a propositura da ação direta de inconstitucionalidade (ADI), não mais restrita ao Procurador-Geral da República, mas estendida também ao Presidente da República e aos Governadores de Estados (Poder Executivo federal e estadual), às Mesas Diretoras do Senado Federal, da Câmara dos Deputados e das Assembleias Estaduais (Poder Legislativo federal e estadual), ao Conselho Federal da Ordem dos Advogados do Brasil, aos partidos políticos com representação no Congresso Nacional, às organizações sindicais e entidades de classe de âmbito nacional. Essa ampliação da legitimidade ativa para o ajuizamento da ADI, reforçada por aqueele "compromisso maximizador" da Constituição Federal de 1988, resultou, também, em um “boom” de ações propostas no modelo concentrado.

É correto dizer, como antes assinalado que o Brasil passou a conviver, efetivamente, com os dois modelos de controle de constitucionalidade das leis (difuso e concentrado) a partir da Constituição Federal de 1988, visto que, antes de 1988, embora houvesse a possibilidade de o STF exercer o controle de constitucionalidade pela via direta (modelo concentrado), prevalecia, de fato, o modelo difuso, com a predominância do recurso extraordinário.

A partir da Constituição Federal de 1988, com a ampliação do modelo concentrado, tornou-se inegável a importância assumida pela ação direta de inconstitucionalidade, que se tornou o modelo preferencial a ser adotado pelo STF. E, passados mais de vinte e cinco anos da vigência da Constituição Federal de 1988, as alterações provocadas na "praxis” brasileira, em razão da importância assumida pela ADI, conduziram a um novo cenário, em que se pode afirmar o surgimento de um peculiar modelo de controle de constitucionalidade brasileiro, resultante do amálgama

Vargas. A Constituição Federal de 1946, promulgada na retomada do regime democrático que se seguiu à derrocada da ditadura de Getúlio Vargas, restabeleceu a figura da ação interventiva, mas esse instrumento foi, de fato, muito pouco utilizado (MENDES, 2005, p. 64/65). A partir da Emenda Constitucional $\mathrm{n}^{\circ}$ 16, de 1965, já na ditadura militar, o modelo concentrado se torna mais efetivo, embora, como já registrado, a limitação em relação à legitimidade ativa para a propositura da representação de inconstitucionalidade tenha tornado secundária a importância do modelo concentrado. 
do modelo concentrado com o modelo difuso (como abordado no tópico subseqüente deste trabalho).

Também teoricamente, a adoção do modelo concentrado de constitucionalidade contribuiria para resolver a crise do STF porque, em vez de julgar centenas (ou milhares) de recursos extraordinários sobre uma única questão constitucional, o STF poderia proferir uma única decisão, em ADI, que teria efeito vinculante em relação a todos os demais órgãos do Poder Judiciário, produzindo eficácia "erga omnes”. No modelo difuso adotado no Brasil, a decisão do STF, em recurso extraordinário, aplicava-se apenas ao caso concreto julgado, não se estendendo para casos idênticos, o que levava o STF a julgar, incontáveis vezes, a mesma questão ${ }^{9}$.

Contudo, embora tenha se tornado, ao longo do tempo, o principal modelo de controle de constitucionalidade no Brasil, o modelo concentrado não resolveu a crise do STF. Ao contrário, pode ser afirmado que a ampliação do modelo concentrado de controle de constitucionalidade contribuiu, em certa medida, para aumentar aquela crise, porque congestionou, ainda mais, o fluxo de processos no STF.

De fato, examinando-se as estatísticas do STF, a partir da vigência da Constituição Federal de 1988 até julho de 2013, vê-se que, no período, foram distribuídas 4.945 ações diretas de inconstitucionalidade. Dessas, a maior parte, 1.969 ADI's (ou cerca de 40\%) não foi conhecida, não tendo havido apreciação do mérito da causa, em razão da extinção preliminar da ADI, pelos mais variados fundamentos (que não interessam ao objetivo deste trabalho).

Considerando-se, então, apenas as ADI's que foram admitidas, isto é, as 2.976 ADI's restantes (cerca de 60\% do total de ADI's, mas aqui consideradas como o total de ADI's avaliadas, isto é, 100\%), 416 ADI's obtiveram decisão liminar (cerca de 14\% das ADI's admitidas), 1.209 ADI's foram definitivamente julgadas no mérito (cerca de $41 \%$ das ações admitidas), e 1.351 ADI's ainda aguardavam julgamento de mérito (cerca de $45 \%$ das ações admitidas) ${ }^{10}$. Portanto, quase a metade das ADI's distribuídas no STF não haviam obtido decisão de mérito, o que é claro sinal de que a crise do STF também alcançou o controle de constitucionalidade pelo modelo concentrado. E o

\footnotetext{
${ }^{9}$ As Constituições brasileiras, inclusive a atual Constituição Federal, de 1988, traziam a previsão de que o Senado Federal poderia, diante de decisão do STF, em controle difuso, pela inconstitucionalidade de determinada norma, editar resolução suspendendo a eficácia da norma impugnada (artigo 52, X, da Constituição Federal de 1988), com o que se produziria efeito análogo ao efeito vinculante e à eficácia contra todos das decisões proferidas no modelo concentrado. O Senado Federal, contudo, sempre foi econômico no uso dessa prerrogativa, de modo que, no mais das vezes, o STF via-se obrigado a julgar incontáveis recursos extraordinários sobre a mesma questão constitucional.

10 Dados disponíveis no "site" do STF, consulta em 23 de dezembro de 2013, disponível em http://www.stf.jus.br/portal/cms/verTexto.asp?servico=estatistica\&pagina=adi.
} 
congestionamento torna-se ainda mais evidente se consideradas as estatísticas relativas às demais ações próprias do modelo concentrado de constitucionalidade.

De fato, além da ADI, o sistema brasileiro de controle de constitucionalidade prevê, ainda, a ação declaratória de constitucionalidade (ADC), criada pela Emenda Constitucional $\mathrm{n}^{\mathrm{o}}$ 3, de 17 de março de 1993 (artigo 102, inciso I, letra $a$, da Constituição Federal de 1988), a ação direta de inconstitucionalidade por omissão (ADO), originariamente prevista na Constituição Federal de 1988 (artigo 103, § 2º e ainda a arguição de descumprimento de preceito fundamental (ADPF), prevista também no texto original da Constituição Federal de 1988 (artigo 102, $\S 1^{\circ}$ ), mas implementada, efetivamente, a partir da edição da Lei $n^{\circ}$ 9.882, de 3 dezembro de 1999. Todos esses instrumentos processuais, se, por um lado, permitiram ampliar imensamente o alcance do controle concentrado de constitucionalidade (elevando o STF ao papel de protagonista principal da vida política brasileira contemporânea), por outro lado, obviamente, resultaram no aumento de ações tramitando no STF, com agravamento da crise.

Portanto, malgrado as várias modificações que houve, tanto em termos de estrutura do Poder Judiciário, como em termos de mecanismos processuais, a crise do STF não se resolveu ao longo do século XX. Aliás, ao longo dos anos, permaneceu - e até se agravou - a incapacidade de o STF julgar todos os feitos que lhe são submetidos. E a busca por soluções para a crise, no mais das vezes, provocou efeitos reflexos negativos e não imaginados, remanescendo, contudo, a crise. ${ }^{11}$ Outras alternativas, assim, passaram a ser implementadas, alternativas essas que resultaram - já se pode ousar fazer a afirmação - em um modelo peculiar de controle de constitucionalidade, fruto do amálgama dos modelos concentrado e difuso.

\footnotetext{
${ }^{11}$ Em trabalho apresentado ao XXIV CONPEDI, Carlos Victor Muzzi Filho examinou uma das soluções tentada ao longo do tempo, qual seja, o aumento das competências monocráticas dos relatores dos processos no STF (e, de modo geral, dos relatores nos tribunais brasileiros) (MUZZI FILHO, 2015). Segundo Muzzi Filho a "estratégia de privilegiar a atuação monocrática dos Ministros foi um dos principais mecanismos empregados pelo STF (e pelos tribunais em geral) para tentar dar conta do caudaloso volume de processos que, a cada ano, é recebido pelo tribunal" (MUZZI FILHO, 2015 p. 448). Sublinhou que, ao privilegiar a atuação monocrática dos Ministros, "o STF viu diminuir acentuadamente o número de decisões colegiadas, registrando Marcos Paulo Veríssimo que 'o percentual de acórdãos publicados em comparação com o número geral de casos julgados tem caído década após década' (VERISSIMO, 2008, p. 417). Assim, se na década de 1940 os acórdãos - decisões colegiadas correspondiam a 'uma média de 83,88\%' dos casos julgados pelo STF, esta média foi reduzida para ' $11,80 \%$, relativa aos sete primeiros anos da década de 2000' (VERISSIMO, 2008, p. 417)” (MUZZI FILHO, 2015, p. 448). Ponderou, então, Carlos Victor Muzzi Filho que essa opção pelas decisões monocráticas "gera preocupações óbvias, relacionados com a possibilidade de haver a pulverização da orientação do STF, que não mais seria a orientação do tribunal, mas desse ou daquele julgador. Nessa linha, Oscar Vilhena Vieira adverte que 'o Supremo poderia melhorar a qualidade de seu processo deliberativo. Em primeiríssimo lugar deveriam ser restringidas, ao máximo, as competências de natureza monocráticas' (VIEIRA, 2009, p. 501)”(MUZZI FILHO, 2015, p. 448).
} 


\section{O CONTROLE DE CONSTITUCIONALIDADE NO INÍCIO DO SÉCULO XXI: O NOVO MODELO E AS PERSPECTIVAS DIANTE DO NOVO CPC}

No início desse século XXI, permanecendo a crise do $S T F$, o sistema brasileiro de controle de constitucionalidade foi, novamente, alvo de profundas modificações, em razão da criação da exigência de repercussão geral da questão constitucional, da definição de rito processual específico para os recursos repetitivos e, ainda, pela criação da súmula vinculante. Essas modificações decorreram da Emenda Constitucional $\mathrm{n}^{\mathrm{o}} 45$, de 2004, a Emenda da Reforma do Judiciário, bem como de diversas alterações efetuadas no Código de Processo Civil de 1973.

Houve alguns efeitos positivos em decorrência das inovações produzidas, mas, como de costume, efeitos indesejados também já começaram a ser percebidos. E a edição do novo Código de Processo Civil, Lei n 13.015 , de 2015, cuja vigência se iniciará em 18 de março de 2016, se insere na mesma linha das propostas implementadas desde a Emenda Constitucional n 45, de 2004, e que, efetivamente, alteraram profundamente o sistema brasileiro de controle de constitucionalidade.

José dos Santos Carvalho Filho, a esse propósito, registra que, especialmente em razão da introdução do requisito da repercussão geral, como condição necessária para a admissão do recurso extraordinário, ocorreu o "fim da bipolaridade. Não existem mais dois sistema de controle de constitucionalidade no Brasil, mas um sistema eclético de jurisdição constitucional, o sistema brasileiro eclético" (CARVALHO FILHO, 2015, p. 87). Prossegue José dos Santos Carvalho Filho:

[...] o sistema de controle de constitucionalidade brasileiro acumula mecanismos tanto do modelo clássico europeu-continental quanto do modelo difuso anglo-saxão, sem conservar características elementares dos inspiradores, razão pela qual se criou algo novo diferente de tudo o que existe no mundo. Assim, não se trata de um modelo dual, mas do sistema brasileiro eclético de jurisdição constitucional (CARVALHO FILHO, 2015, p. 92/93).

Esse fenômeno apontado por Carvalho Filho, como assinalado, tem como principal causa a criação da repercussão geral da questão constitucional, novo requisito de admissibilidade introduzido pela Emenda Constitucional no 45, de 2004. Dispõe o artigo 102, § 3º da Constituição Federal de 1988 (acrescentado pela Emenda Constitucional $\mathrm{n}^{\circ} 45$, de 2004), que "no recurso extraordinário o recorrente deverá 
demonstrar a repercussão geral das questões constitucionais discutidas no caso, nos termos da lei, a fim de que o Tribunal examine a admissão do recurso, somente podendo recusá-lo pela manifestação de dois terços de seus membros”.

Após a alteração do texto constitucional, foi necessário aguardar a iniciativa do legislador ordinário, o que ocorreu com a edição da Lei $\mathrm{n}^{\circ} 11.418$, de 19 de dezembro de 2006, que acrescentou o artigo 543-A e o artigo 543-B, ambos do ainda vigente Código de Processo Civil de 1973. Além da regulamentação legal, foi necessária, também, alteração do Regimento Interno do STF, a quem o legislador atribuiu a função de regulamentar vários aspectos do procedimento de aplicação da repercussão geral, de modo que somente com a edição, pelo STF, da Emenda Regimental n ${ }^{\circ} 21$, de 30 de abril de 2007, tornou-se aplicável a exigência do requisito da repercussão geral da questão constitucional.

Não é objetivo deste trabalho discutir o instituto da repercussão geral da questão constitucional, sendo suficiente realçar o fato de que sua exigência contribuiu, decisivamente, para a chamada objetivação do recurso extraordinário (MANCUSO, 2013, p. 197), eis que a admissão do recurso extraordinário dependerá da existência de uma relevante questão econômica, social, jurídica ou política, que extrapole os interesses subjetivos da causa, como dispõe o artigo 543-A, § $1^{\circ}$, do CPC/1973.

Há que se observar, contudo, que a introdução da exigência de repercussão geral da questão constitucional faz lembrar a antiga classificação que se fazia das normas constitucionais, distinguindo-as entre normas materialmente constitucionais, cujo conteúdo dizia respeito à "forma de Estado", ao "modo de aquisição e exercício do poder", à "estruturação dos órgãos de poder" e aos "limites de sua ação", enquanto as normas formalmente constitucionais seriam aquelas que, "rigorosamente falando, não têm conteúdo constitucional. Ou seja, regras que não dizem respeito à matéria constitucional (forma do Estado, forma de governo etc.)" (FERREIRA FILHO, 1994, p. 10/11).

Essa distinção entre normas materialmente e formalmente constitucionais (que alguns autores denominam normas superiores e normas inferiores, respectivamente) foi criticada pela doutrina e pela jurisprudência do próprio STF, que, ao julgar a ADI $n^{\circ}$ 810, Pleno, Relator Min. Moreira Alves, recusou expressamente tal distinção:

[...] A tese de que há hierarquia entre normas constitucionais originárias dando azo à declaração de inconstitucionalidade de umas em face de outras e incompossível com o sistema de Constituição rígida. [...]

Por outro lado, as cláusulas pétreas não podem ser invocadas para sustentação da tese da inconstitucionalidade de normas constitucionais 
inferiores em face de normas constitucionais superiores, porquanto a Constituição as prevê apenas como limites ao Poder Constituinte derivado ao rever ou ao emendar a Constituição elaborada pelo Poder Constituinte originário, e não como abarcando normas cuja observância se impôs ao próprio Poder Constituinte originário com relação as outras que não sejam consideradas como cláusulas pétreas, e, portanto, possam ser emendadas.

É claro que a criação da exigência da repercussão geral visou dotar o STF da prerrogativa de filtrar os temas que serão apreciados pela corte, na via do recurso extraordinário. Mas esse filtro, claro, pode significar a criação de normas constitucionais inferiores, cuja violação não ensejaria a apreciação pelo STF, na via do recurso extraordinário.

Certo é que, havendo o reconhecimento da repercussão geral de determinada questão constitucional, o STF apreciará apenas um recurso extraordinário, que servirá de paradigma, sobrestando-se o andamento de todos os demais recursos extraordinários que discutam aquela mesma questão constitucional (artigo 543-B, “caput” e $\S 1^{\circ}$, do CPC/1973). Posteriormente, a decisão de mérito sobre a questão constitucional com repercussão geral deverá ser estendida a todos os casos análogos (artigo 543-B, § $2^{\circ}$, § $3^{\circ}$ e $\S 4^{\circ}$, do CPC/1973). E mesmo a decisão do STF que negue a existência de repercussão geral deverá ser seguida pelos demais tribunais, servindo como fundamento para se negar admissão aos outros recursos extraordinários que versem a mesma questão (artigo 543-A, § 5º do CPC/1973).

Dessa maneira, a decisão do STF, ainda que na via do controle difuso de constitucionalidade, já não mais terá efeito limitado apenas àquele caso julgado, mas será estendida a todos os demais casos similares. Anota José dos Santos Carvalho Filho que, com a exigência da repercussão geral, "houve a racionalização do modo de prestação jurisdicional, pois o Supremo Tribunal Federal passou a julgar apenas o processo-paradigma de cada tema, no qual firma a tese que orienta a resolução de todos os casos com idêntica controvérsia” (CARVALHO FILHO, 2015, p. 45).

Nesse cenário, uma das principais características do modelo difuso de controle de constitucionalidade, qual seja, a limitação dos efeitos da decisão às partes envolvidas na ação julgada, deixa de existir no modelo brasileiro de controle de constitucionalidade. A decisão proferida pelo STF, nos recursos extraordinários em que reconhecida a repercussão geral da questão constitucional, produz efeitos para além dos limites subjetivos da ação julgada, porque "sobreleva o interesse público, ou social" (MANCUSO, 2013, p. 197).

E a sistemática da repercussão geral foi aprofundada pelo CPC/2015, que definiu o rito dos chamados recursos repetitivos, válido, tanto para o recurso extraordinário, 
quanto para o recurso especial (artigos 1.036 a 1.041).

O CPC/1973, convém frisar, instituiu o rito dos recursos repetitivos apenas para o recurso especial (artigo 543-C), mas, como assinala Cassio Scarpinella Bueno, o CPC/1973, na prática, "foi além da identificação da repercussão geral a partir de casos repetitivos, passando-se, também, ao julgamento dos recursos repetitivos" (BUENO, 2015, p. 549).

Dessa maneira, seja no âmbito do recurso extraordinário, quanto do recurso especial, o CPC/2015 padronizou a resolução das questões constitucionais (recurso extraordinário) ou questões de direito federal (recurso especial) repetitivas, regulando, assim, "mais uma técnica destinada a viabilizar a criação de precedentes vinculantes, a serem usado como padrões decisórios que terão de ser seguidos pelos órgãos jurisdicionais brasileiros quando do exame de casos nos quais se discutam as mesmas questões de direito" (CÂMARA, 2015, p. 548) ${ }^{12}$.

Novamente sob o ponto de vista exclusivamente teórico, a criação da repercussão geral seria relevante instrumento para reduzir o número de recursos extraordinários julgados pelo STF, dada a possibilidade de se restringir as questões constitucionais passíveis de apreciação pelo STF. Na prática, contudo, efeitos inesperados e indesejados já são percebidos.

Não há negar, segundo as estatísticas do STF, a grande redução no número de recursos extraordinários tramitando no STF, pois, se em 2006 (antes da implantação da repercussão geral), foram 54.575 recursos extraordinários distribuídos no STF, em 2007, com a implantação da repercussão geral durante aquele ano, o número já havia sido reduzido para 49.708 recursos extraordinários. Desde então, o número de recursos extraordinários vem sofrendo sensível redução: 21.531, em 2008; 8.348, em 2009; 6.042 em 2012; e 3.805 em 2013.

Em relação ao instituto da repercussão geral, contudo, constata-se que, na maior parte dos casos apreciados, o STF reconheceu a existência de repercussão geral nas questões constitucionais. Até dezembro de 2013, segundo dados coletados por Luis Roberto Barroso, Ministro do STF, o STF havia reconhecido a existência de repercussão geral em 493 questões constitucionais diferentes, negando essa repercussão em 199 outras questões. Assim, em 70\% do total de 696 casos submetidos à sua apreciação, o STF reconheceu a presença de repercussão geral nas questões deduzidas

12 O CPC/2015 criou, ainda, outros mecanismos para resolver a litigiosidade de massa, como, notadamente, o Incidente de Resolução de Demandas Repetitivas (IRDR), disciplinado nos artigos 976 a 987. Mas esse $I D D R$ não se refere, necessariamente, a questões constitucionais, razão pela qual é abordado o presente trabalho. 
nos recursos extraordinários (BARROSO, 2014, p. 8).

E dessas 493 questões constitucionais com repercussão geral reconhecida, o STF havia julgado o mérito de apenas 163 questões, restando 330 diferentes questões a serem apreciadas (BARROSO, 2014, p. 8). Portanto, o STF havia julgado apenas 33\% da questões constitucionais com repercussão geral reconhecida, motivo pelo qual, segundo Luis Roberto Barroso, "seriam necessários mais de 7 (sete) anos para liquidar o estoque", considerando a média por ela apurada de 44 temas julgados por anos (BARROSO, 2014, p. 9). E advertiu: "E isso em um cenário contrafactual e indesejável, no qual não se reconheceria qualquer nova repercussão geral ao longo dos próximos anos" (BARROSO, 2014, p. 9).

Nesse cenário, não causa surpresa o número alarmante de recursos extraordinários sobrestados nos diversos tribunais inferiores, aguardando o julgamento das questões cuja repercussão geral foi reconhecida pelo STF. Considerando-se dados até setembro de 2015, estariam sobrestados cerca de 1.300 .000 (um milhão e trezentos mil) recurso extraordinários, todos aguardando a resolução das questões cuja repercussão geral foi reconhecida ${ }^{13}$. Assim, se se diminuiu o acúmulo de recursos extraordinários no STF, nem por isso se resolveu o acúmulo de processos no Poder Judiciário, apenas se transferindo do STF para os tribunais inferiores o congestionamento de processos acumulados.

A repercussão geral da questão constitucional, pensada como instrumento para resolver, definitivamente, a crise do STF, tornou-se mais uma parte dessa crise. Por isso, Joaquim Falcão e Ivar A. Hartmann, examinando as estatísticas do STF a partir de 2011, chegam a conclusão de que a "última grande tentativa de transformar o Supremo em uma corte constitucional minimamente viável, a EC 45, até agora falhou" (FALCÃO; HARTMANN, 2015, p. 488) ${ }^{14}$.

Compreende-se, então, a sugestão feita por Luis Roberto Barroso, que propõe, por assim dizer, uma reforma da repercussão geral, sugerindo que o STF passe a reconhecer, por semestre, apenas dez questões com repercussão geral, por considerar “impensável que o STF reconheça mais repercussões gerais do que seja capaz de julgar

13 Dados constantes dsite" do STF, disponíveis em http://www.stf.jus.br/portal/cms/verTexto.asp?servico=estatistica\&pagina=sobrestadosrg, consulta realizada em 20 de janeiro de 2016.

14 Joaquim Falcão e Ivar Hartmann ainda apuraram o aumento do número de agravo em recurso extraordinário (ARE), recurso cabível quando os recursos extraordinários não são admitidos pelos tribunais de origem (tribunais recorridos). Embora essa questão extrapole o objetivo deste trabalho, temse ainda mais um efeito indesejado da reforma pensada para resolver a crise do STF, afirmando os autores citados que "a principal conquista da EC 45 para o Supremo está gravemente ameaçada", em razão do “crescimento do número de AREs autuados" (FALCÃO; HARTMANN, 2015, p. 487). 
em um período de um ano. Isso contribui para a percepção social da morosidade e ineficiência da Justiça. É preciso enfrentar e superar essa voracidade de aceitar mais do que se pode julgar" (BARROSO, 2014, p. 9).

Nessa toada, as alterações feitas pelo CPC/2015, que, em verdade, aprofundam as tentativas iniciadas com a Emenda Constitucional $\mathrm{n}^{\circ} 45$, de 2004, notadamente a criação da repercussão geral, são vista com certa descrença, porque apenas aumentam a dose do remédio que já se afigura insuficiente. Se o STF, ao longo desse século XXI, não vem conseguindo julgar as causas com repercussão geral reconhecida, não há porque se imaginar que irá conseguir julgar as causas repetitivas.

O compromisso maximizador da Constituição Federal, que torna constitucional questões que, rigorosamente, jamais deveriam alcançar esse "status" jurídico, aliado ao acúmulo de competências jurisdicionais do STF, apontam para uma visão pessimista em relação aos efeitos do CPC/2015, que dificilmente logrará resolver a crise do STF, apenas aumentando a dose do remédio que já se mostra ineficaz.

\section{PONDERAÇÃO FINAL}

Encerrando este trabalho, e sem a pretensão de apontar conclusões, os autores assinalam que a crise do STF tem sua origem, ao fim e ao cabo, no acúmulo de competências do Supremo Tribunal Federal, que não é, e nunca foi, uma corte exclusivamente constitucional.

É inegável, cumpre pontuar, a necessidade de se reduzir o volume de processos submetidos ao STF. Esse sempre foi o objetivo principal de todas as reformas implementadas ao longo do tempo: impedir o aumento do número de processos a ser apreciado pela corte. Todas as reformas que se pautaram por esse objetivo falharam, o que permite aventar que a redução definitiva do volume de processos exigira complexas e profundas reformas, que reduzam o número de competências jurisdicionais hoje atribuídas ao STF, "competências superlativas", na expressão de Oscar Vilhena Vieira (VIEIRA, 2009, p. 489/491, “passim”).

A Constituição Federal de 1988, sabidamente, atribuiu inúmeras competências jurisdicionais do STF, não sendo hiperbólica a imagem do "múltiplo Supremo", afirmada por Joaquim Falcão, Pablo de Camargo Cerdeira e Diego Werneck Arguelhes, quando observam que o STF se comporta "como três cortes distintas, com três personas 
fundidas em apenas uma instituição" (FALCÃO; CERDEIRA; e ARGUELHES, 2011, p. 17).

Referem-se Falcão, Cerdeira e Arguelhes às funções exercidas pelo STF, no plano jurisdicional (sem considerar, pois, atribuições de índole administrativa), como: a) corte constitucional propriamente dita (controle concentrado de constitucionalidade); b) corte recursal (recursos extraordinários e ordinários); e c) corte de única instância (ações originárias), atribuições triplas que fazem multiplicar o número de feitos submetidos a cada ano ao STF.

O próprio Supremo Tribunal Federal reconhece essa necessidade de redução de suas competências, e ainda que de forma pontual, vem procurando alternativas pontuais, como as alterações regimentais que transferiram para as turmas do STF competências que, anteriormente, eram atribuídas ao Plenário do tribunal (BARROSO, 2014, p. 2), buscando desafogar a congestionada pauta do Plenário. Mas esses ajustes internos são manifestamente insuficientes, porque apenas tangenciam o ponto nevrálgico da questão.

Em um país com uma Constituição extremamente analítica, apenas o papel de corte constitucional já resultaria em enorme volume de causas, em razão daquele compromisso maximizador já mencionado. Haveria que se cogitar, até mesmo, de uma redução dos temas a serem apreciados pelo STF, como já permitido com a definição das questões que tenham, ou não tenham, repercussão geral. Impossível é tentar resolver a crise preservando as outras múltiplas competências do STF. Como ponderado por Luis Roberto Barroso, em afirmação que deve ser repetida, faz-se necessário "enfrentar e superar essa voracidade de aceitar mais do que se pode julgar” (BARROSO, 2014, p. 9).

Mas esta redução de competências, no atual estágio da história brasileira, dificilmente se tornará realidade, razão pela qual todas as reformas implementadas e ensaiadas parecem ter o mesmo destino de apenas alimentar a crise do STF, ainda que de modo involuntário.

\section{REFERÊNCIA}

AZEVEDO, Philadelpho. A crise do Supremo Tribunal. "In": Arquivos do Ministério da Justiça. Rio de Janeiro: Ministério da Justiça, vol. 1, 1943, p. 7-18.

BARROSO, Luís Roberto. Reflexões sobre as competências e o funcionamento do Supremo Tribunal Federal. 2014. Disponível em

http://www.luisrobertobarroso.com.br/?m=201408, consulta em 20 de janeiro de 2015. 
BUENO, Cassio Scarpinella. Manual de direito processual civil. São Paulo: Saraiva, 2015 .

BUZAID, Alfredo. A crise do Supremo Tribunal Federal. "In": Revista da Faculdade de Direito da USP. São Paulo: USP, vol. 55, 1960, p. 327-372.

CÂMARA, Alexandre Freitas. O novo processo civil brasileiro. São Paulo: Atlas, 2015.

CANOTILHO, José Joaquim Gomes. Direito constitucional. $7^{\mathrm{a}}$ edição $-17^{\mathrm{a}}$ reimpressão. Coimbra: Almedina, 2003.

CAPPELLETTI, Mauro. O controle judicial de constitucionalidade das leis no direito comparado. Tradução brasileira de Aroldo Plínio Gonçalves. Porto Alegre: Sergio Antonio Fabris Editor, 1984.

CARVALHO FILHO, José dos Santos. Repercussão geral: balanço e perspectivas. São Paulo: Almedina, 2015.

CONTINENTINO, Marcelo Casseb. História do controle de constitucionalidade das leis no Brasil - Percursos do pensamento constitucional no século XIX (1824-1891). São Paulo: Almedina, 2015.

FALCÃO, Joaquim; CERDEIRA, Pablo de Camargo; e ARGUELHES, Diego Werneck. I Relatório Supremo em números - O múltiplo Supremo. Rio de Janeiro: Escola de Direito da Fundação Getúlio Vargas, 2011. Disponível em 〈http:supremoemnumeros.fgv.br〉.

FIORAVANTI, Maurizio. Constitución - De la Antigüedad a nuestros días. Tradução espanhola de Manuel Martínez Neira. $1^{\text {a }}$ edición - $1^{\text {a }}$ Reimpressión. Madrid: Editorial Trotta, 2007.

GABBAY, Daniela Monteiro; e CUNHA, Luciana Gross (organizadoras).

Litigiosidade, morosidade e litigância repetitiva no Judiciário - Uma análise empírica. São Paulo: Saraiva, 2012.

GALVÃO, Ilmar Nascimento. Poder Judiciário - Reforma de 1988 - O recurso especial no Superior Tribunal de Justiça. "In": Recursos no Superior Tribunal de Justiça.

TEIXEIRA, Sálvio de Figueiredo (coordenador). São Paulo: Saraiva, 1991, p. 83-89.

MANCUSO, Rodolfo de Camargo. Recurso extraordinário e recurso especial. 12a edição. São Paulo: Revista dos Tribunais, 2013.

MENDES, Gilmar Ferreira. COELHO, Inocêncio Mártires; e BRANCO, Paulo Gustavo 
Gonet. Curso de direito constitucional. 2a edição. São Paulo: Saraiva e IDP, 2008.

MENDES, Gilmar Ferreira. Jurisdição constitucional. 5a edição. São Paulo: Saraiva, 2005 .

MUZZI FILHO, Carlos Victor. O relator e a medida cautelar em Ação Direta de Inconstitucionalidade: crítica à jurisprudência do Supremo Tribunal Federal. "In":

Política judiciária, gestão e administração da justiça [Recurso eletrônico on-line]. Organização CONPEDI/UFMG/FUMEC/Dom Helder Câmara; Coordenadores: Claudia Maria Barbosa, Sérgio Henriques Zandona Freitas, Lucas Gonçalves Da Silva Florianópolis: CONPEDI, 2015, p. 441-464.

SILVA, José Afonso da. Do recurso extraordinário no direito processual brasileiro. São Paulo: Revista dos Tribunais, 1963.

SUNDFELD, Carlos Ari; RIZZI, Ester Gammardella; CARDOSO, Evorah Lusci Costa et alii. Controle de Constitucionalidade e judicialização: o STF frente à sociedade e aos Poderes. Belo Horizonte: Fafich, 2010.

VIEIRA, Oscar Vilhena. Supremocracia. In: Filosofia e teoria constitucional contemporânea. SARMENTO, Daniel (coordenador). Rio de Janeiro: Lumen Juris, 2009 , p. 48 
